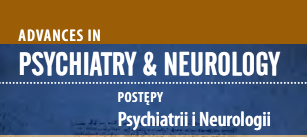

Correspondence to:

Katarzyna Nowakowska-Domagała Instytut Psychologii

ul. Smugowa 10/12

91-433 Łódź

tel. +48 696-417-907

e-mail:

katarzyna.nowakowskadomagala@uni.lodz.pl

Submitted: 04.10.2020

Accepted: 08.11.2020

\section{CLINICAL PRESENTATION, SEXUAL FUNCTION AND QUALITY OF LIFE AS PREDICTORS OF SEXUAL SATISFACTION AMONG WOMEN WITH URINARY INCONTINENCE BEFORE A VAGINAL REVITALIZATION PROCEDURE}

\author{
Malwina Soja', Wojciech Grabczak², \\ Katarzyna Nowakowska-Domagała ${ }^{3}$ (D), Rafał Grabczak4 , \\ Tadeusz Pietras ${ }^{5}$, Łukasz Mokros ${ }^{6}$ (D)

\begin{abstract}
'Department of Operative Gynaecology and Gynaecological Oncology, Polish Mother's Memorial Hospital-Research Institute in Lodz, Poland Memorial Hospital Research Institute in Lodz, Poland Institute of Psychology University of Lodz, Poland

${ }^{4}$ Non-public health care institution "Profmed”, Krasnystaw, Poland

Institute of Psychiatry and Neurology, Second Department of Psychiatry, Warsaw, Poland

${ }^{6}$ Department of Clinical Pharmacology, Medical University of Lodz, Poland
\end{abstract} \\ ${ }^{2}$ Department of Oncological Surgery and Breast Diseases, Institute of Polish Mother's
}

\begin{abstract}
Purpose: Urinary incontinence (UI) is a common condition among women that affects quality of life, depressive symptoms and sexual function. The aim of the study was to verify whether clinical data, sexual dysfunction and quality of life may be independent predictors of life satisfaction of women with UI.

Methods: The study group included 76 patients who reported to a gynaecological clinic for vaginal revitalisation due to symptoms typical of UI. The patients completed: Life Satisfaction Questionnaire (FLZ), Female Sexual Function Index (FSFI), Incontinence Quality of Life Questionnaire (I-QOL) and Beck Depression Inventory (BDI).

Results: The UI patients presented a lower mean score regarding satisfaction with sex than a comparable healthy population. A high score on the FLZ-sex scale was predicted by lack of labour complications, a high score on the FLZ-health and FLZ-relationships scales, and FSFI arousal scale.

Conclusions: UI appears to be linked particularly strongly to low satisfaction with sex as a dimension of life satisfaction. Memory of labour complications was associated to dissatisfaction with sex. On the other hand, no link between satisfaction with sex and episiotomy, caesarean section or natural childbirth was found. High satisfaction with sex was linked to high satisfaction with general health and relationship, as well as high arousal as a sexual function.
\end{abstract}

Key words: satisfaction with sex, urinary incontinence, depressive symptoms.

\section{PURPOSE}

The World Health Organization (WHO) defines health as not just the absence of disease, but the presence of full mental, physical and social well-being. Hence, in today's research paradigm, disease is often assessed not only in terms of symptomatology and prognosis, but also how it affects quality of life and life satisfaction. Although these concepts are often used interchangeably, they have slightly different meanings [1]. A determination of quality of life (QoL) entails a subjective assessment of daily functioning, and is often evaluated in the context of health (health related quality of life - HRQL). This evaluation usually comprises at least three key aspects: social, psychological and physical $[1,2]$. In contrast, life satisfaction represents a more general, yet comprehensive, con- 
scious assessment of life. An undeniably interesting issue is the impact of chronic illness on the perception of life satisfaction of the patient: a value related to well-being and, hence, with the positive aspects of life. In the area of gynaecology, the degree of life satisfaction has been examined among women suffering from polycystic ovary syndrome [3], premature ovarian failure [4] or infertility [5]. However, no studies have yet assessed the level of life satisfaction in a population of women experiencing urinary incontinence (UI).

The International Continence Society defines UI as a lack of control in the retention of urine (complaint of involuntary loss of urine) [6]. Depending on the cause, this can be divided into two general types: stress UI, characterised by urinary leakage during physical effort, sneezing or coughing, and urge UI, characterised by urinary leakage preceded by a sudden feeling, and an incapacity to control the need to pass urine. In addition, UI can also manifest as a range of combinations of the two, as well as other rarely observed causes. UI is a common condition (depending on the study and age of the patient, the incidence ranges from $5 \%$ to $69 \%$ [7]), which can significantly impair quality of life [8-10], exacerbate depressive symptoms [11-13] and cause widespread sexual dysfunction $[14,15]$. UI is also mentioned as a risk factor for low life satisfaction, particularly in the elderly population [16].

The purpose of this paper is to evaluate life satisfaction and its individual dimensions among women with UI, and to determine independent predictors of sexual satisfaction.

\section{METHODS}

\section{Characteristics of the study group}

The study group comprised 79 patients who reported to a gynaecological clinic in the period 2015-2016 for revitalization of intimate areas by $\mathrm{CO}_{2}$ fractional laser treatment. Each of the women had typical symptoms of UI: urinary leakage during exercise, sneezing, lifting or resting, sudden urges to urinate and frequent urination at night. The symptoms had occurred at least once in the month preceding the visit. Patients were informed about the purpose of the study, and about the anonymity and confidentiality of the results. The main inclusion criterion was informed consent. The exclusion criteria comprised a pre-existing or present diagnosis of psychiatric or neurological disorders, severe chronic disease, and experience of trauma (e.g. accident, death of a loved one) during the six months preceding the study. The research followed the principles of the Declaration of Helsinki.

Based on the above criteria, three patients were excluded from the study. Therefore, 76 women were included in the final analysis.

\section{Questionnaires}

\section{Life satisfaction}

The Polish adaptation of the FLZ (Fragebogen zur Lebenszufriedenheit) Questionnaire of Life Happiness was used to evaluate life satisfaction $[17,18]$. The questionnaire consists of 10 spheres including health, work, finances, free time, children, self, friends, accommodation, relationships and sex, as well as other general indicators of life satisfaction. Each sphere contains seven statements scored from 1 (very dissatisfied) to 7 (very satisfied).

\section{Sexual dysfunction}

To measure sexual dysfunction among the study population we used a version [19] of the Female Sexual Function Index [20], standardized for Polish subjects. The questionnaire consists of 19 questions about six areas: desire, arousal, lubrication, orgasm, satisfaction and pain. The answers are scored from 0 to 6 . Higher results indicate better sexual function: a score of 0 means no sexual activity for four weeks. In the present study, sexual dysfunction was assumed for a score of 27.5 points or less.

\section{Ul-specific quality of life}

The Polish version of the I-QOL (Incontinence Quality of Life) [21] was used to evaluate quality of life. The questionnaire consists of 22 questions that assess three domains: avoidance and limiting behaviour, psychosocial impact and social embarrassment. Higher scores imply better quality of life.

\section{Depressive symptoms}

The Polish version of the BDI (Beck Depression Inventory) was used to evaluate symptoms of depression [22]. It consists of 21 questions scored from 0 to 3 . A higher total score indicates more severe depressive symptoms. A score of 11 or more points was assumed to indicate the presence of depressive symptoms.

\section{Questionnaire}

In addition, a questionnaire was created for the purpose of the study. It was used interviews, and covered obstetric and gynaecological history, socio-demographic data and general medical history.

\section{Statistical analysis}

Statistical analysis was performed using SPSS 24.0 (Predictive Solutions). Continuous variables were characterised by mean (M) and standard deviation (SD). The test group consisted of more than 50 people. Thus, the limit theorem was used and the verification of normal distribution was abandoned [23]. Homogeneity of intergroup variance was studied using Levene's test. The Stu- 
Clinical presentation, sexual function and quality of life as predictors of sexual satisfaction among women with urinary incontinence before a vaginal revitalization procedure

Table 1. A comparison of the studied group of women with urinary incontinence (UI) with a similar sample of women from a healthy population with regard to individual dimensions of the Fahrenberg Life Satisfaction Questionnaire (FLZ) (Polish version)

\begin{tabular}{|c|c|c|c|c|c|c|c|}
\hline \multirow{2}{*}{ FLZ - dimensions } & \multicolumn{2}{|c|}{ Healthy $(n=356)$} & \multicolumn{2}{|c|}{$\mathrm{UI}(n=76)$} & \multirow{2}{*}{$t$} & \multirow{2}{*}{$p$} & \multirow{2}{*}{$p$ corr. } \\
\hline & M & SD & M & SD & & & \\
\hline Health & 34.14 & 6.96 & 34.99 & 6.590 & 1.120 & 0.266 & 0.325 \\
\hline Profession & 34.15 & 7.49 & 31.82 & 11.290 & -1.802 & 0.075 & 0.104 \\
\hline Finances & 30.4 & 7.68 & 33.34 & 6.885 & 3.725 & $<0.001$ & $<0.001$ \\
\hline Free time & 34.04 & 7.85 & 34.49 & 7.322 & 0.532 & 0.596 & 0.656 \\
\hline Children & 39.83 & 7.13 & 40.33 & 8.476 & 0.513 & 0.609 & 0.609 \\
\hline Oneself & 35.9 & 6.39 & 37.96 & 5.090 & 3.529 & 0.001 & 0.002 \\
\hline Friends and acquaintances & 35.32 & 6.03 & 37.55 & 4.579 & 4.250 & $<0.001$ & $<0.001$ \\
\hline Residence & 35.81 & 6.28 & 38.54 & 5.656 & 4.207 & $<0.001$ & $<0.001$ \\
\hline Relationship/marriage & 38.43 & 8.69 & 35.88 & 11.219 & -1.980 & 0.051 & 0.081 \\
\hline Sex & 36.63 & 8.33 & 34.24 & 7.480 & -2.789 & 0.007 & 0.012 \\
\hline Total score & 242.23 & 31.08 & 359.13 & 44.440 & 22.933 & $<0.001$ & $<0.001$ \\
\hline
\end{tabular}

$M$ - mean, SD - standard deviation, $t$-Student's t-test, $p$ - probability according to the Student's t-test, $p$ corr. -the probability for the test, taking into account Benjamin-Hochberg adjustments

dent's $t$-test for one sample was used to compare the mean values of the individual FLZ scales with those of a similar population studied by Chodkiewicz [18]. A multivariant linear regression model was constructed to evaluate the predictive value of selected clinical, socio-demographic and psychological parameters for the assessment of satisfaction with sex. The reverse elimination method was used. The final model was evaluated with regard to the lack of autocorrelations (Durbin-Watson test), homoscedasticity and collinear constraints between variables (tolerance). Linear regression results are presented as non-standardised parameters (B), standard error (SE) and standardized parameters $\beta$ [24]. The level of statistical significance was assumed to be $\alpha=0.05$.

\section{RESULTS}

\section{Life satisfaction - comparison with the healthy population}

The tested subjects demonstrated a significantly lower mean score on the FLZ-satisfaction with sex scale than the healthy population identified by Chodkiewicz [18]. However, the women with UI reported significantly higher scores with regard to satisfaction with finance, satisfaction with self, friends and acquaintances, and a higher overall score compared to the healthy women. No significant difference in mean score was observed on the health, profession, free time, children or relationship/marriage scales (Table 1).

\section{Predictors of satisfaction with sex}

A linear regression model was constructed by means of stepwise elimination. The variables thought to poten-
Table 2. Table of frequencies of qualitative variables selected as potential explanatory variables for satisfaction with sex in the test sample

\begin{tabular}{|l|c|c|}
\hline Factor & $n$ & $\%$ \\
\hline $\begin{array}{l}|l| \\
\text { Smoking }\end{array}$ & 6 & 7.9 \\
\hline \begin{tabular}{l} 
Stress incontinence \\
\hline 1 degree
\end{tabular} & 16 & 21.1 \\
\hline 2 degree & 22 & 28.9 \\
\hline 3 degree & 8 & 10.5 \\
\hline Urge incontinence & 19 & 25.0 \\
\hline Current infection & 7 & 9.2 \\
\hline Number of natural births & \multicolumn{2}{|l|}{} \\
\hline 1 & 22 & 28.9 \\
\hline 2 & 34 & 44.7 \\
\hline 3 & 8 & 10.5 \\
\hline 4 & 2 & 2.6 \\
\hline
\end{tabular}

Number of caesarean sections

\begin{tabular}{|l|c|c|}
\hline 1 & 9 & 11.8 \\
\hline 2 & 2 & 2.6 \\
\hline 3 & 1 & 1.3 \\
\hline Birth complications & 10 & 13.2 \\
\hline \begin{tabular}{l}
$|l|$ \\
\hline Degree of episiotomy
\end{tabular} & 33 & 43.4 \\
\hline 1 degree & 11 & 14.5 \\
\hline 2 degree & 2 & 2.6 \\
\hline 3 degree & 9 & 11.8 \\
\hline Perineal rupture & 9 & 11.8 \\
\hline HTZ or oestrogen preparations & 22 & 28.9 \\
\hline Intrauterine insertion & 8 & 10.5 \\
\hline Oral contraceptives & & \\
\hline HTZ- hormone replacement therapy
\end{tabular}

HTZ - hormone replacement therapy 
Table 3. Descriptive statistics for continuous variables selected as potentially explaining satisfaction with sex in the study group

\begin{tabular}{|l|c|c|}
\hline \multicolumn{1}{|c|}{} & M & SD \\
\hline Age & 44.74 & 10.98 \\
\hline BMI & 24.35 & 3.88 \\
\hline FSFI desire & 3.25 & 1.23 \\
\hline FSFI arousal & 3.37 & 1.68 \\
\hline FSFI lubrication & 3.73 & 1.92 \\
\hline FSFI orgasm & 3.54 & 1.92 \\
\hline FSFI pain & 3.79 & 2.24 \\
\hline I-QOL ALB & 56.43 & 20.23 \\
\hline I-QOL PS & 56.58 & 22.34 \\
\hline I-QOL SE & 48.58 & 23.58 \\
\hline BDI & 7.13 & 6.30 \\
\hline
\end{tabular}

tially explain the FLZ sex score are presented in Tables 2 and 3, with the additional inclusion of the FLZ-health, FLZ-self and FLZ-relationship/marriage variables (Table 1 ). The model was constructed in 23 steps. It was found that the model fit the empirical data $(\mathrm{df}=4, F=20.420$, $\mathrm{df}$ $=4, p<0.001)$. The coefficient of determination (R2) was 0.535 . The following factors were found to be significant predictors of a positive outcome on the FLZ-sex scale: lack of complications during labour reported in the interview, a positive result on the FLZ-health and FLZ-relationships scales, and FSFI arousal. No significant relationship was found between satisfaction with sex and the following parameters: age, BMI, smoking, level of urge or stress UI, presence of symptoms of genitourinary system infections, number of natural births, number of caesarean sections, history of episiotomy, perineal rupture during

Table 4. The results of the linear regression model of satisfaction with sex (FLZ-sex) in the sample of women with urinary incontinence

\begin{tabular}{|c|c|c|c|c|c|}
\hline Factor & B & SE & $\beta$ & $t$ & $p$ \\
\hline (Intercept) & 13.636 & 3.779 & & 3.608 & 0.001 \\
\hline Birth complications (0 - no, 1 - yes) & -5.530 & 1.801 & -0.252 & -3.070 & 0.003 \\
\hline FSFI arousal & 1.842 & 0.407 & 0.415 & 4.529 & 0.000 \\
\hline FLZ health & 0.216 & 0.103 & 0.191 & 2.104 & 0.039 \\
\hline FLZ relationship & 0.210 & 0.055 & 0.316 & 3.858 & 0.000 \\
\hline \multicolumn{6}{|l|}{ Variables excluded from the model } \\
\hline Age & & & 0.106 & 1.153 & 0.253 \\
\hline BMl & & & -0.022 & -0.245 & 0.807 \\
\hline Tobacco smoking $(0-$ no, 1 -yes $)$ & & & -0.122 & -1.487 & 0.142 \\
\hline Degree of stress UI ( 0 - none, from 1 to 3 - degree) & & & -0.029 & -0.351 & 0.727 \\
\hline Urge UI (0 - no, 1 - yes) & & & 0.055 & 0.667 & 0.507 \\
\hline Current genitourinary tract infection & & & 0.054 & 0.626 & 0.533 \\
\hline Number of natural births & & & -0.013 & -0.151 & 0.881 \\
\hline Number of caesarean sections & & & -0.022 & -0.248 & 0.805 \\
\hline Degree of episiotomy ( 0 - none, from 1 to 3 - degree) & & & -0.140 & -1.722 & 0.089 \\
\hline Perineal rupture $(0$ - no, 1 - yes $)$ & & & -0.008 & -0.094 & 0.925 \\
\hline HTZ or oestrogen preparations ( 0 - no, 1 - yes) & & & 0.035 & 0.411 & 0.682 \\
\hline Interuterine insertion ( 0 - no, 1 - yes) & & & -0.032 & -0.379 & 0.706 \\
\hline Oral contraception ( $0-$ no, $1-$ yes $)$ & & & 0.059 & 0.720 & 0.474 \\
\hline FLZ self & & & 0.084 & 0.839 & 0.404 \\
\hline FSFI lubrication & & & -0.081 & -0.601 & 0.550 \\
\hline FSFI desire & & & 0.048 & 0.428 & 0.670 \\
\hline FSFI orgasm & & & 0.055 & 0.422 & 0.675 \\
\hline FSFI pain & & & -0.153 & -1.246 & 0.217 \\
\hline ।-QOL ALB & & & -0.037 & -0.394 & 0.695 \\
\hline ।-QOL SE & & & -0.021 & -0.234 & 0.816 \\
\hline ।-QOL PS & & & 0.016 & 0.168 & 0.867 \\
\hline $\mathrm{BDI}$ & & & -0.125 & -1.206 & 0.232 \\
\hline
\end{tabular}


birth, the use of HTZ, oestrogen preparations, oral contraception or IUDs, nor with the results of the FLZ-self, FSFI-lubrication, desire, orgasm, pain, I-QOL ALB, SE, PS or BDI in the test sample (Table 4).

\section{DISCUSSION}

The first part of the work compares life satisfaction among women with UI with healthy women from a Polish population described by Chodkiewicz [18]. The women in the test group only scored worse than the control group with regard to satisfaction with sex. Previous reports suggest that UI may negatively affect sexual function. Su et al. found UI to be a risk factor for poor lubrication during intercourse and dyspareunia. In a paper by Dogan et al., women with UI evaded sexual activity and reported lack of sexual satisfaction and anorgasmia more often compared to the control group [25]. One possible explanation assumes that women with UI avoid sexual contact because of the fear of passing urine during intercourse or an unpleasant smell $[26,27]$. It should be noted that older age and somatic comorbidity may be additional risk factors of poor satisfaction with sex. Thus, the need for screening for sexual dysfunction and sex dissatisfaction among all women with UI is emphasized, e.g. by means of simple self-report questionnaires $[15,28]$.

Interestingly, women suffering from UI reported significantly higher overall satisfaction with life and finances, and with self, friends and homes, relative to the control group. This is most likely due to the specificity of the test group; it was not formed from randomly-selected women, but those who reported for commercial treatment with relatively higher costs. It can be assumed that the participants were women who were relatively wealthy, and material resources typically accompany personal resources, high self-evaluation and a support network in the form of friends and acquaintances [29].

The second part of the work identified independent predictors of the occurrence of low satisfaction with sex among the women tested. One predictor was low satisfaction with health, but not type of UI nor the degree of severity of stress UI. Presumably, the self-perception of the disease itself, and not necessarily its progress, may have an impact on the enjoyment of sex. It was previously found that individuals suffering from serious mental disorders complained of worse satisfaction with sex compared to the control group [30]. For the women with UI, it was reported that somatic comorbidity and depressive symptoms were risk factors for poor satisfaction with sex [15]. The aforementioned papers indirectly confirm the results of the present study.

Another strong predictor of low satisfaction with sex was low satisfaction with relationships. This appears to be consistent with previous findings concerning non-clinical samples. Heiman et al. reported that the satisfaction with sex is closely related to the satisfaction with relationships in a group of over one thousand pairs from five countries [31].The women who trusted their partner, felt more secure in the relationship, and could openly talk about sex were more satisfied with their intimate lives [32, 33].

Childbirth complications were defined in our questionnaire as prolongation of the second stage of labour. This is when a woman feels the strongest cramps, and therefore the most pain; it can lead to a traumatic birth injury, and is accompanied by the greatest fear for the newly-born baby [34, 35]. It is interesting to note that this is another strong independent predictor of dissatisfaction with sex in the tested group. On the other hand, no link between satisfaction with sex and episiotomy, caesarean section or natural childbirth was found. It is possible that apprehension of a subsequent pregnancy and similar experiences during labour prevent the women from feeling full satisfaction with sex. The memory of the childbirth as a complicated one may indicate e.g. the negative emotionality of the patient, which is related to poor satisfaction with sex and greater concentration on the medical symptoms [36-38]. However, those conclusions are highly speculative and require further investigation.

The final strong predictor of low satisfaction with sex was a low evaluation of arousal in the FSFI questionnaire. Arousal affects the degree of lubrication during intercourse, and thus dyspareunia, and ultimately the overall assessment of satisfaction with sex [39].

Previous publications have discussed the possibility of dissatisfaction with sex or poor evaluation of sexual function being linked to episiotomy, caesarean section or natural childbirth; however, our findings did not indicate these factors to be independent predictors, most likely due to the distance in time of the evaluation from the birth: they are most influential during the puerperal period and for a short time afterwards [40].

Most women used contraceptives based on vaginal inserts with progesterone. Previous studies have shown this probably does not have any influence on sexual function $[41,42]$.

No link between satisfaction with sex and depressive symptoms or UI-related quality of life was found in the present study. This stands in opposition to the previous findings [43]. However, it should be remembered that lack of statistically significant associations does not mean lack of associations. It may be assumed that depression and quality of life prove to be predictors of satisfaction with sex in the case of a larger sample or use of different questionnaires. This thesis requires verification in future studies.

It is important to emphasise that this is the first work to evaluate life satisfaction in women suffering from UI. It arises from field of research that perceives UI as an interdisciplinary problem. Although UI is not an illness that shortens lifespan, it nevertheless has an influence on 
the everyday activities of women, their satisfaction with life and their sexual function. Without a doubt, the importance of this issue should not be underestimated. It is necessary to carry out a thorough interview with patients, bearing in mind that those affected often do not report IU symptoms themselves $[44,45]$, and to offer multidirectional and comprehensive medical and psychological care.

\section{STUDY LIMITATIONS}

One limitation was that the study group was not formed at random; it was carried out as a naturalistic observation. Nevertheless, the sample reflects clinical reality because the women who reported to the gynaecologist did so with UI symptoms as the main cause. Another limitation was that the test group was relatively small, and the study was retrospective. Future studies should be based on larger groups and assess variation in the studied parameters over time; they should also examine how the surgical and non-surgical treatment of UI influences improvement in life satisfaction within its individual spheres.

\section{CONCLUSIONS}

UI appears to be linked particularly strongly to low satisfaction with sex as a dimension of life satisfaction. Memory of labour complications was associated to dissatisfaction with sex. On the other hand, no link between satisfaction with sex and episiotomy, caesarean section or natural childbirth was found. High satisfaction with sex was linked to high satisfaction with general health and relationship, as well as high arousal as a sexual function.

\section{Conflict of interest}

Absent.

Financial support

Absent.

\section{References}

1. Bartels M. Genetics of wellbeing and its components satisfaction with life, happiness, and quality of life: a review and meta-analysis of heritability studies. Behav Genet 2015; 45: 137-156.

2. Diener E, Suh EM, Lucas RE, Smith HL. Subjective well-being: three decades of progress. Psychol Bull 1999; 125: 276-302.

3. Cipkala-Gaffin J, Talbott EO, Song MK, Bromberger J, Wilson J. Associations between psychologic symptoms and life satisfaction in women with polycystic ovary syndrome. J Womens Health (Larchmt) 2012; 21: 179-187.

4. Liao KL, Wood N, Conway GS. Premature menopause and psychological well-being. J Psychosom Obstet Gynaecol 2000; 21: 167-174.

5. Ben Shlomo S, Pascal M, Taubman Ben-Ari O, Azuri Y, Horowtz E. Life satisfaction of women in early stages of fertility treatment. Women Health 2016; 19: 1-17.

6. Haylen BT, de Ridder D, Freeman RM, Swift SE, Berghmans B, Lee J, et al. An International Urogynecological Association (IUGA)/International Continence Society (ICS) joint report on the terminology for female pelvic floor dysfunction. Neurourol Urodyn 2010; 29: 4-20.

7. Milsom I, Altman D, Cartwright R, Lapitan MC, Nelson R, Sillen U, et al. Epidemiology of Urinary Incontinence (UI) and other Lower Urinary Tract Symptoms (LUTS), Pelvic Organ Prolapse (POP) and Anal Incontinence (AI). ICUD-EAU, 2013.

8. Coyne KS, Wein AJ, Tubaro A, Sexton CC, Thompson ChL, Kopp ZS, et al. The burden of lower urinary tract symptoms: evaluating the effect of LUTS on health-related quality of life, anxiety and depression: EpiLUTS. BJU Int 2009; 103 Suppl 3: 4-11.

9. Ko Y, Lin S, Salmon J, Bron M. The impact of urinary incontinence on quality of life of the elderly. Am J Manag Care 2005; 11 (4 Suppl): 103-111.

10. Lang K, Alexander IM, Simon J, Sussman M, Lin I, Menzin J, et al. The impact of multimorbidity on quality of life among midlife women: Findings from a U.S. nationally representative survey. J Womens Health (Larchmt) 2015; 24: 374-383.

11. Melville JL, Delaney K, Newton K, Katon W. Incontinence severity and major depression in incontinent women. Obstet Gynecol 2005; 106: 585-592.

12. Hung K, Awtrey C, Tsai A. Urinary incontinence, depression, and economic outcomes in a cohort of women between the ages of 54 and 65 years. Obstet Gynecol 2014; 123: 822-827.

13. Tettamanti G, Altman D, Iliadou AN, Bellocco R, Pedersen NL. Depression, neuroticism, and urinary incontinence in premenopausal women: a nationwide twin study. Twin Res Hum Genet 2013; 16: 977-984. 
14. Su CC, Sun BYC, Jiann BP, Naumann G. Editorial comment to association of urinary incontinence and sexual function in women. Int J Urol 2015; 22: 114.

15. Appa AA, Creasman J, Brown JS, Van Den Eeden SK, Thom DH, Subak LL, et al. The impact of multimorbidity on sexual function in middle-aged and older women: beyond the single disease perspective. J Sex Med 2014; 11: 2744-2755.

16. Pinto JM, Neri AL. Factors associated with low life satisfaction in community-dwelling elderly: FIBRA Study. Cad Saude Publica 2013; 29: 2447-2458.

17. Fahrenberg E, Myrtek J, Schumacher M, Brähler J. Fragebogen zur Lebenszufriedenheit (FLZ). Handanweisung. Göttingen: Hogref; 2000.

18. Chodkiewicz J. Adaptacja polska Kwestionariusza Zadowolenia z Życia (FLZ) [Polish Adaptation of Life Satisfaction Questionnaire]. Stud Psychol 2009; 47: 5-21.

19. Nowosielski K, Wróbel B, Sioma-Markowska U, Poręba R. Development and validation of the Polish version of the Female Sexual Function Index in the Polish population of females. J Sex Med 2013; 10: 386-395.

20. Rosen R, Brown C, Heiman J, Leib S. The Female Sexual Function Index (FSFI): a multidimensional self-report instrument for the assessment of female sexual function. J Sex Marital Ther 2000; 26: 191-208.

21. Patrick DL, Martin ML, Bushnell DM, Yalcin I, Wagner TH, Buesching DP. Quality of life of women with urinary incontinence. Further development of the incontinence quality of life instrument (I-QOL). Urology 1999; 53: 71-76.

22. Zawadzki B, Popiel A, Pragłowska E. Psychometric properties of the Polish version of the Aaron T. Beck's Depression Inventory BDI. Psychol Etol Genet 2009; 19: 71-95.

23. Szymczak W. Podstawy statystyki dla psychologów. Podręcznik akademicki. Wydanie drugie poprawione. Warszawa: Wydawnictwo Difin; 2010.

24. Slinker BK, Glantz SA. Multiple linear regression: accounting for multiple simultaneous determinants of a continuous dependent variable. Circulation 2008; 117: 1732-1737.

25. Doğan K, Vural M, Akyüz F. Evaluation of effects of urinary incontinence subtypes on women's sexual function using the Golombok - Rust Inventory of Sexual Satisfaction. J Obstet Gynaecol Res 2017; 43: 551-556.

26. Mendes A, Hoga L, Gonçalves B, Silva P, Pereira P. Adult women's experiences of urinary incontinence: a systematic review of qualitative evidence. JBI Database System Rev Implement Rep 2017; 15: 1350-1408.

27. Visser E, de Bock GH, Berger MY, Dekker JH. Impact of urinary incontinence on sexual functioning in community-dwelling older women. J Sex Med 2014; 11: 1757-1765.

28. Karbage SAL, Santos ZSMA, Frota MA, de Moura HJ, Vasconcelos CTM, Neto JAV, et al. Quality of life of Brazilian women with urinary incontinence and the impact on their sexual function. Eur J Obstet Gynecol Reprod Biol 2016; 201: 56-60.

29. Ali A, Ambler G, Strydom A, Rai D, Cooper C, McManus S, et al. The relationship between happiness and intelligent quotient: the contribution of socio-economic and clinical factors. Psychol Med 2013; 43: 1303-1312.

30. Östman M. Low satisfaction with sex life among people with severe mental illness living in a community. Psychiatry Res 2017; 216: 340-345.

31. Heiman JR, Long JS, Smith SN, Fisher WA, Sand MS, Rosen RC. Sexual satisfaction and relationship happiness in midlife and older couples in five countries. Arch Sex Behav 2011; 40: 741-753.

32. Montesi JL, Conner BT, Gordon EA, Fauber RL, Kim KH, Heimberg RG. On the relationship among social anxiety, intimacy, sexual communication, and sexual satisfaction in young couples. Arch Sex Behav 2013; 42: 81-91.

33. Mark KP, Jozkowski KN. The mediating role of sexual and nonsexual communication between relationship and sexual satisfaction in a sample of college-age heterosexual couples. J Sex Marital Ther 2013; 39: 410-427.

34. Allen VM, Baskett TF, O'Connell CM, McKeen D. Maternal and perinatal outcomes with increasing duration of the second stage of labor. Obstet Gynecol 2009; 113: 1248-1258.

35. Laughon SK, Berghella V, Reddy UM, Sundaram R, Lu Z, Hoffman MK. Neonatal and maternal outcomes with prolonged second stage of labor. Obstet Gynecol 2014; 124: 57-67.

36. Ratner ES, Erekson EA, Minkin MJ, Foran-Tuller KA. Sexual satisfaction in the elderly female population: a special focus on women with gynecologic pathology. Maturitas 2011; 70: 210-215.

37. Demir SE, Rezvani A, Ok S. Assessment of sexual functions in female patients with ankylosing spondylitis compared with healthy controls. Rheumatol Int 2013; 33: 57-63.

38. Kim SR, Nho JH, Nam JH. Relationships among type-D personality, symptoms and quality of life in patients with ovarian cancer receiving chemotherapy. J Psychosom Obstet Gynecol 2018; 39: 289-296.

39. Burri A, Hilpert P, Spector T. Longitudinal evaluation of sexual function in a cohort of pre- and postmenopausal women. J Sex Med 2017; 12: 1427-1435.

40. Eid MA, Sayed A, Abdel-Rehim R, Mostafa T. Impact of the mode of delivery on female sexual function after childbirth. Int J Impot Res 2015; 27: 118-120.

41. Xu X, Macaluso M, Frost J, Anderson JE, Curtis K, Grosse SD. Characteristics of users of intrauterine devices and other reversible contraceptive methods in the United States. Fertil Steril 2017; 96: 1138-1144.

42. Higgins JA, Sanders JN, Palta M, Turok DK. Women's sexual function, satisfaction, and perceptions after starting long-acting reversible contraceptives. Obstet Gynecol 2016; 128: 1143-1151.

43. Senra C, Pereira MG. Quality of life in women with urinary incontinence. Rev Assoc Med Bras 2015; 61: 178-183.

44. Duralde ER, Walter LC, Van Den Eeden SK, Nakagawa S, Subak LL, Brown JS, Thom DH, et al. Bridging the gap: determinants of undiagnosed or untreated urinary incontinence in women. Am J Obstet Gynecol 2017; 214: 266.e1-266.e9.

45. Margalith I, Gillon G, Gordon D. Urinary incontinence in women under 65: quality of life, stress related to incontinence and patterns of seeking health care. Qual Life Res 2004; 13: 1381-1390. 